\section{¿RAÚL, TE ACUERDAS...? NERUDA Y GONZÁLEZ TUÑóN ANTE LA GUERRA CIVIL ESPAÑOLA}

\author{
Pedro Mendiola OÑate
}

\section{Pedro Mendiola Oñate}

Subdirector del Área de América Latina de la Biblioteca Virtual Miguel de Cervantes Saavedra. Ha centrado su actividad investigadora en la poesía argentina de vanguardia, tema al que ha dedicado diversos trabajos críticos, entre los que destaca el libro Buenos Aires entre dos calles: breve panorama de la vanguardia poética argentina (2001). Ha colaborado en la edición electrónica de Nuevos textos para la Literatura Hispanoamericana colonial (2000).

\section{Para Nélida y Adolfo}

Encuentro casi por casualidad una anécdota que tal vez no sea muy conocida. Entre el 21 y el 25 de junio de 1935 tuvo lugar en $\mathrm{Pa}$ rís el I Congreso de Intelectuales en Defensa de la Cultura, al que asistieron, entre otros muchos escritores, los dos protagonistas de esta intervención: Pablo Neruda y Raúl González Tuñón. El suceso al que me refiero lo cuenta el poeta español Arturo Serrano Plaja, quien, como integrante de la delegación española, había viajado a París junto a ambos poetas precisamente:

Neruda, González Tuñón y yo fuimos a parar al Hotel Bréa, en Montparnasse. E hicimos una especie de convenio: para prolongar la estancia en París cuanto fuese posible, con el no mucho dinero que teníamos (la mayor parte lo ponía Neruda) decidimos hacer un «plan de austeridad» o algo por el estilo. Y como en París encontramos a Vallejo (alimentado de casi exclusivamente patatas cocidas mañana y noche, como cuando le conocí en España) el plan parecía sobrevenir del modo más natural [...]

Acaso me salió el inquisidor español, una mañana «sorprendí»-digamos- a Neruda y Tuñón tomando una ensaimada con el café crême en el Dâme, me indigné y les hice dolidos reproches. A los cuales Pablo Neruda, con sonrisa de hermano mayor o algo por el estilo y recordando que ese mismo día yo había salido más tarde del hotel porque había ido a pedir la llave del cuarto de baño para ducharme con agua fría (y luego aclaro el punto), Neruda, repito a mis reproches contestó «en verso»:

\section{El delegado de España \\ No come pero se baña.}

Y gracias a esa «indirecta» vine a saber que, en Francia, incluso la ducha fría que yo tomaba, «pasa» sistemáticamente a la cuenta ${ }^{1}$.

Es un relato que concuerda perfectamente con la imagen que tenemos del Neruda de esos años, más dado a la tertulia amable y a la francachela que a la contienda social y a la asamblea política. Pero, evidentemente, la camaradería poética entre Neruda y González Tuñón tiene un interés más allá de lo puramente anécdotico. La relación entre ambos se había iniciado en aquel singular Buenos Aires de 1933, que como dice un tango de ese mismo año, bostezaba «de pena y placer». También bostezaba de pena y placer Neruda en la capital porteña, donde la vida disoluta de banquetes, tertulias, estrenos teatrales y agasajos nocturnos, le ayudaba a sobrellevar aquel cansancio «de ser hombre» que le provocaba su anodino desempeño consular:

Con un traje de perro y una mancha en la frente caigamos a la profundidad de los papeles, a la ira de las palabras encadenadas, a manifestaciones tenazmente difuntas, a sistemas envueltos en amarillas hojas.

Rodad conmigo a las oficinas, al incierto olor de ministerios, y tumbas, y estampillas. Venid conmigo al día blanco que se muere dando gritos de novia asesinada 2 .
1 Arturo Serrano Plaja, «Dos cartas de Arturo Serrano Plaja», en Manuel Aznar Soler, II Congreso Internacional de Escritores para la Defensa de la Cultura (1937): literatura española y antifascismo (1927-1939), Valencia, Conselleria de Cultura, Educació i Ciència de la Generalitat Valenciana, 1987, pp. 380-381.

2

Pablo Neruda, "Desespediente», Residencia en la Tierra 2, en Obras completas, Barcelona, Galaxia Gutenberg, 1999, vol. I, pp. 310-311.
¿Raúl, te acuerdas...? Neruda y González Tuñón ante la Guerra Civil española PEDRO MENDIOLA OÑATE 


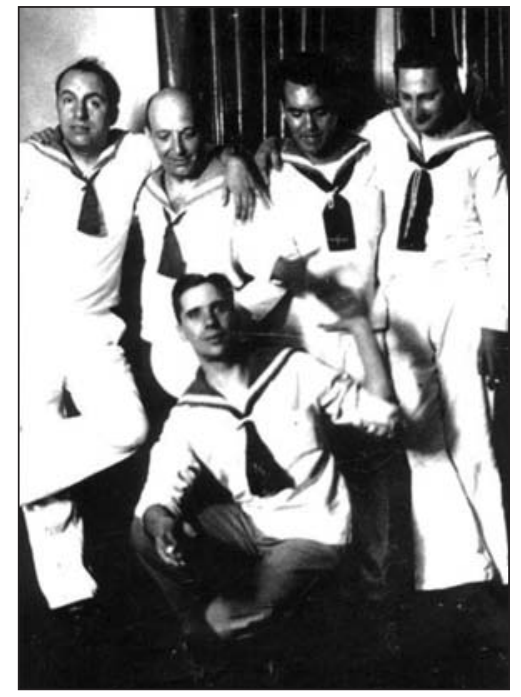

Neruda, Lorca y González Tuñón en Buenos Aires (1933).

3

Pablo Neruda, Confieso que he vivido, Madrid, Unidad Editorial, 1999, p. 119.

4

García Lorca se refiere a estas circunstancias en una entrevista concedida al diario Crítica a su llegada a Buenos Aires: «si bien hay en España una fuerte reacción de derecha, el pueblo español, que ama y gusta la libertad, está en la izquierda» («Vengo de torero herido y a dar 4 conferencias...», Crítica, Buenos Aires, 14 de octubre de 1933).

5

Cfr. Jorge Schwartz (ed.), Homenaje a Girondo, Buenos Aires, Corregidor, 1987, p. 216.

6

José Luis Romero, Las ideas politicas en Argentina, Buenos Aires, Fondo de Cultura Económica, 2002, p. 244.

7

El editorial del primer número de Unidad por la defensa de la cultura (Buenos Aires, enero de 1936, p. 1), órgano de la Agrupación de Intelectuales, Artistas, Periodistas y Escritores (AIAPE), recogía esta frase atribuida al ministro de Propaganda e Instrucción pública de Hitler.

¿Raúl, te acuerdas...? Neruda y González Tuñón ante la Guerra Civil española PEDRO MENDIOLA OÑATE

Neruda había llegado a Buenos Aires en agosto de 1933 con un cargo de agregado al consulado chileno en la capital porteña. El año anterior se había visto obligado a abandonar su peregrinaje consular por los distintos «archipiélagos, costas y arrecifes» $»^{3}$ del sureste asiático y regresar a su país. La crisis política en Chile, reflejo periférico del declive económico del 29, había provocado la dimisión del presidente Carlos Ibáñez en 1931 y el retorno de buena parte del cuerpo diplomático chileno. Y casi al mismo tiempo que Neruda, en octubre de 1933, llegaba a Buenos Aires Federico García Lorca; venía para promocionar el estreno de $\mathrm{Bo}-$ das de sangre a cargo de la compañía de Lola Membrives. España en ese momento vivía también una compleja situación política, agravada por la victoria electoral de las derechas y la entrada al gobierno de Alejandro Lerroux, en noviembre de $1933^{4}$.

Sin duda, la presencia de Neruda y de García Lorca en Buenos Aires había reactivado en cierta medida el ambiente intelectual de una ciudad que no brillaba ya con la misma exultación artística de la década anterior. Tal vez el último gran gesto vanguardista sea la presentación del libro Espantapájaros de Oliverio Girondo, que en 1932 se había paseado durante quince días por la ciudad en una carroza coronaria tirada por seis caballos ${ }^{5}$. Sin embargo, desde el golpe de 1930 y especialmente, como señala José Luis Romero, desde la llegada también en 1933, del embajador alemán Edmund von Thermann, «la influencia de la doctrina hitlerista y de sus métodos de acción comenzaron a predominar» ${ }^{6}$ entre los numerosos grupos filofascistas que orbitaban en torno al gobierno de Agustín P. Justo. La Argentina había abierto la puerta a un ismo muy

8

Al principio de Todos bailan. (Los poemas de Juancito Caminador) (1935), advertía González Tuñón: «En este libro no figura el poema 'Las brigadas de choque'. No puede figurar por imposición del proceso que, a raíz de la publicación de ese poema en Contra, se me sigue. Después de permanecer cinco días de- tenido, recobré la libertad por no tener condena anterior ni antecedentes policiales de ninguna especie, como lo demuestra el documento cuya copia fotográfica exhibió en la Cámara el diputado Ramiconi. El proceso sigue su curso» (Raúl González Tuñón, La calle del agujero en la media. Todos bailan, Buenos Aires, Espasa Calpe, 1994, pág. 124). distinto de los que habían revolucionado el campo artístico argentino en la década anterior. Parecía imponerse el lema acuñado por Goebbels: "Cuando oigo la palabra cultura le saco el seguro a mi revólver» ${ }^{7}$. La creciente presión hacia los medios de comunicación y la rigurosa vigilancia sobre todas las manifestaciones culturales cercanas al pensamiento de izquierdas, tuvieron tal vez, uno de sus exponentes más significativos en la detención y encarcelamiento de Raúl González Tuñón por la publicación de su poema «Las brigadas de choque» en la revista Contra ${ }^{8}$.

Neruda había desembarcado en la capital argentina con la maleta llena de nuevos libros: acababa de publicar El hondero entusiasta, escrito diez años atrás, y por fin, después de sucesivos desengaños editoriales, Residencia en la tierra. Portaba también el embrión de los poemas que compondrán la segunda Residencia. González Tuñón, más comprometido que nunca en la denuncia social, preparaba también un nuevo libro de poemas, El otro lado de la estrella. Ambos poetas comenzaban entonces a distanciarse de la retórica vanguardista, de un atenuado imaginismo de acento surrealista por el lado del chileno; de un cierto regusto cosmopolita a lo Barnabooth, por el del argentino. Por otro lado, si Neruda había apuntado tímidamente su sensibilidad obrera en algunos escritos juveniles y en un par de poemas de su Crepusculario; González Tuñón evidenciaba ya una inclinación hacia las cuestiones de índole social que, si bien no había cuajado con plenitud en su labor de poeta, sí estaba ideológicamente delimitada en su desempeño como redactor del diario Crítica. No obstante, a pesar de esa esbozada «sensibilidad» social, en una carta al escritor argentino Héctor Eandi ese año de 1933, manifestaba todavía Neruda un persistente escepticismo, una casi declarada neutralidad, respecto de la política y sus circunstancias:

En realidad, políticamente, no se puede ser ahora sino comunista o anticomunista. Las demás doctrinas se han ido desmoronando y cayendo. Pero esto es para los que son políticamente, esto es, existen civilmente. Yo fui anarquista hace años, redactor del periódico síndico-anarquista Claridad, en donde publiqué mis ideas y cosas por primera vez. Y todavía me queda esa desconfianza del anarquista hacia las formas del Estado, hacia la política impura. Pero creo 
que mi punto de vista de intelectual romántico no tiene importancia?.

\section{SOBRE UNA POLÍTICA SIN PUREZA}

En mayo de 1934 Neruda era trasladado al Consulado de Chile en Barcelona, destino que tras unos meses conseguiría permutar por el de Madrid, que ocupaba en aquel tiempo su amiga y mentora Gabriela Mistral. La llegada a la capital española, le permitió introducirse en el ambiente intelectual madrileño y apuntalar su aureola de poeta con la publicación de las dos partes de Residencia en la tierra, en la editorial de la revista Cruz y Raya (1935), y con la dirección de la revista Caballo verde para la poesía (octubre 1935 - enero 1936). En Madrid prorroga Neruda la vida de «intelectual romántico» en tertulias y reuniones, en las que coincide nuevamente con Lorca, e inicia tratos con Alberti, Serrano Plaja, Altolaguirre o Miguel Hernández. En Madrid, Neruda se reencuentra también con el poeta argentino Raúl González Tuñón que había llegado de Buenos Aires en enero de 1935.

El ambiente intelectual español de la década del treinta no era demasiado diferente al de otros países: últimas ceremonias para despedir a las vanguardias; viejas y nuevas querellas sobre la pureza o la impureza del arte; florecimiento de una «nueva sensibilidad» artística en torno a la política y a la lucha de clases, etc. En este sentido, el alzamiento de los mineros asturianos en octubre de 1934, último baluarte de la «revolución de octubre» española, sirvió de fermento de este proceso intelectual ${ }^{10}$, provocando una extraordinaria repercusión internacional, de la que se hicieron eco también algunos de los participantes en el I Congreso de Intelectuales en Defensa de la Cultura, celebrado en París, y que sirvió de marco a la anécdota que comentaba al inicio.

La represión del levantamiento minero fue encomendada al general Francisco Franco, quien desde el Ministerio de la Guerra ordenó el envío de la Legión Extranjera a la cuenca minera asturiana. Se calcula -informa Hugh Thomas- «que murieron unas 1300 personas durante la campaña (y, oficialmente, durante la represión) y que unas 3000 resultaron heridas» ${ }^{11}$. En junio de 1935 Neruda y González Tuñón viajan a París junto a Arturo Serrano Plaja para asistir al mencionado congreso en compañía de la delegación española encabeza- da por Julio Álvarez del Vayo. No tuvieron participación activa, sino que se limitaron a asistir a las diferentes asambleas y a firmar alguna que otra declaración colectiva. En un artículo redactado por Andrés Carranque de Ríos aparecen las firmas del argentino y del chileno, junto a las de Álvarez del Vayo y Serrano Plaja, ratificando el contenido social y político del congreso y respaldando una noción abiertamente marxista de la cultura:

Ha tenido el Congreso, en verdad, una significación política, en cuanto política es preocupación por la posible convivencia, ordenación y gobierno de los pueblos. $\mathrm{O}$ a la inversa, que es por consiguiente la misma, de oposición al aislamiento, al desorden y al desgobierno y anarquía realizados en nombre de la no política. La cultura entendida así no se queda reducida a los cultivados, a los intelectuales o escritores, sino que forzosamente llega hasta los planos más elementales, hasta los que tienen menos acceso a la cultura, hasta los planos más populares ${ }^{12}$.

El congreso había sido impulsado por escritores alemanes, rusos y franceses, principalmente, con la unión intelectual ante el ascenso del fascismo en Europa como principal argumento. Uno de los asuntos más ampliamente debatidos fue el de la «función social del escritor», aunque el Congreso sirvió, entre otras derivaciones, para certificar la «autopsia» del movimiento surrealista, que quedó prácticamente excluido de la organización y de las discusiones ${ }^{13}$. Lo cierto es que el congreso dejó, con sus lógicas polémicas y suspicacias, algunas intervenciones memorables, como las de André Gide o de Henri Barbusse, que tratarían de delimitar la función del arte y de sus cultores en la sociedad contemporánea. Tal vez allí comenzara Neruda a perder su desconfianza en la «política impura»:

Quizás muchos retrocederán ante su repugnancia frente a lo que llaman política -dice en su ponencia Henri Barbusse-. No dejemos deformar el sentido de la palabra política con el pretexto de que los políticos que nos dirigen son unos fantoches o gente deshonesta. [...] El verdadero sentido de la palabra política, es: realización social. Todo progreso social es un producto político...14.
Citado por Margarita Aguirre, Genio y figura de Pablo Neruda, Buenos Aires, Eudeba, 1964, p. 141. La cursiva es mía.

10

En el prólogo a Llanto de Sangre de Emilio Prados (Madrid-Valencia, Ediciones Españolas, 1937, pág. 6), decía ya Manuel Altolaguirre: «Fue necesario que llegara el año de la sangrienta represión de Asturias para que todos, todos los poetas, sintiéramos como un imperioso deber de adaptar nuestra obra, nuestras vidas, al movimiento liberador de España». Cito por Manuel Aznar Soler, I Congreso Internacional de Escritores para la Defensa de la Cultura (París, 1935), Valencia, Conselleria de Cultura, Educació i Ciència, 1987, vol. I, p. 35.

11

Hugh Thomas, La guerra civil española, París, Ruedo Ibérico, 1967, p. 95.

12

«Los escritores y el pueblo», Linea, núm. 1, 29 octubre 1935, pág. 4. Reprod. en Manuel Aznar Soler, op. cit., Apéndice 2, documento núm. 26.

Cfr. André Breton, Conversaciones (1913-1952), México, Fondo de Cultura Económica, 1987 pp. 166-171.

14

Henri Barbusse, «Nación y cultura», Monde, núm. 342, 27 junio 1935, pp. 6-8. Cito por Manuel Aznar Soler, op. cit., pp. 298-299.

¿Raúl, te acuerdas...? Neruda y González Tuñón ante la Guerra Civil española PEDRO MENDIOLA OÑATE 


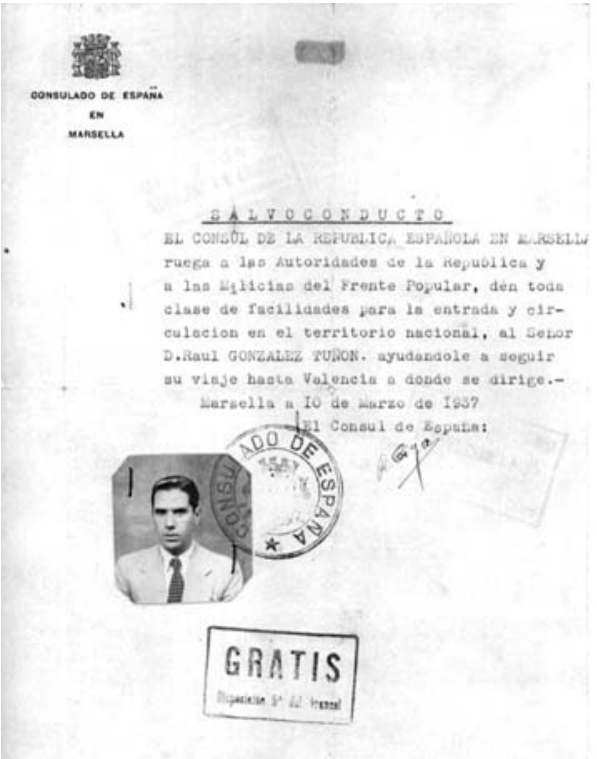

Salvoconducto (España, 1937) [Archivo Nélida Rodríguez Marqués].

15

El poema, que luego sería titulado genéricamente "La libertaria», había aparecido en la revista Milicia popular (Madrid, año I, núm. 63 , 7 de octubre de 1936, p. 2), en un número conmemorativo del alzamiento minero de Asturias.

16

Raúl González Tuñón, «Prólogo», La rosa blindada, 2. ${ }^{\circ}$ ed., Buenos Aires, Ediciones Horizonte, 1962.

17

Amado Alonso, Poesía y estilo de Pablo Neruda. Interpretación de una poesía hermética, Buenos Aires, Editorial Sudamericana, 1977, pp. 348-349.

18

Pablo Neruda, «Las furias y las penas», Tercera residencia, en Obras completas I, Barcelona, Galaxia Gutenberg, 1999, p. 357.

19

Conviene matizar, no obstante, el papel de Neruda en la creación de la revista Caballo Verde: "la dirección de la revista, por una actitud de cortesía se la dimos a él. Pero la revista era nuestra: nosotros la costeábamos, elegíamos el material, la imprimíamos, la encuadernábamos y la distribuíamos por las librerías. No sé

¿Raúl, te acuerdas...? Neruda y González Tunón ante la Guerra Civil española PEDRO MENDIOLA OÑATE

20
Finalmente, la principal motivación de la delegación española, la cuestión de la revolución de Asturias, quedó solapada entre las múltiples discusiones que suscitó el congreso, y salvo alguna breve alusión de solidaridad, como la de Romain Rolland, se limitó a la intervención española que corrió a cargo de Julio Álvarez del Vayo.

González Tuñón, espoleado por la tragedia de los mineros, había escrito ya en Buenos Aires un par de poemas («Aída Lafuente» ${ }^{15}$, «El tren blindado de Mieres»), que a su llegada a España comenzaron a circular, incluso en forma anónima, por medios orales y escritos. En septiembre de 1935 González Tuñón participaba en un acto organizado por León Felipe en el Ateneo de Madrid, donde leía estos y otros poemas «revolucionarios», compuestos ya en España, que integrarán más tarde su libro La rosa blindada (1936). «Y allí estaba entre el público, precisamente»-recuerda con cierta reticencia González Tuñón«el querido Pablo Neruda»:

Pablo era decididamente antifascista, claro está, y simpatizó profundamente con los mineros astures y los obreros madrileños durante aquellos días de «Octubre rojo». Sonreía cuando yo le insté a reflejar en algún poema esos sentimientos ${ }^{16}$.

Son los momentos previos a su transición poética, a su «conversión al prójimo» ${ }^{17}$ como

por qué todo el mundo se ha empeñado en creer que la revista la hizo él. Neruda solo fue un director simbólico, que nosotros nombramos como gesto de generosidad con la poesía americana» (Paloma Ulacia Altolaguirre y Concha Méndez, Memorias habladas, memorias armadas, Madrid, Mondadori, 1990, p. 97. Tomo la cita de Federico Suárez, Intelectuales antifascistas, Madrid, Rialp, 2002).

Pablo Neruda, «Sobre una poesía sin pureza», Caballo verde para la poesía, Madrid, la definiera Amado Alonso. Tanto es así, que Neruda, cinco años después, siente la necesidad de anteponer una nota explicatoria al poema «Las furias y las penas», escrito en ese tiempo: «En 1934 fue escrito este poema. Cuántas cosas han sobrevenido desde entonces! España donde lo escribí, es una cintura de ruinas». Y concluye declarando: «El mundo ha cambiado, y mi poesía ha cambiado» ${ }^{18}$. Un mes después del recital del Ateneo, aparecía el primer número de Caballo verde para la poesía, la revista que "dirigía»19 Neruda y editaban Manuel Altolaguirre y Concha Méndez. A modo de prólogo, encabezaba la revista el famoso texto de Neruda: «Sobre una poesía sin pureza». El asunto no era nuevo, lo habían tratado ya Paul Valéry y el abad Bremond en Francia, Jorge Guillén en España o el mismo González Tuñón en Argentina, a través una encuesta en la revista Contra. La motivación de este y de los otros escritos de Neruda que aparecen en la revista, lejos de presentar un programa definido, hay que buscarla tal vez -como apunta Rodríguez Monegal-, en la querella con Juan Ramón Jiménez por el liderazgo del campo poético de esos años, en un momento en que todavía eran posibles las disputas exclusivamente literarias. Aparte de cuestiones circunstanciales, el texto de Neruda seguía apuntando claves para entender su evolución poética:

Así sea la poesía que buscamos, gastada como por un ácido por los deberes de la mano, penetrada por el sudor y el humo, oliente a orina y azucena, salpicada por las diversas profesiones que se ejercen dentro y fuera de la ley.

Una poesía impura como un traje, como un cuerpo, con manchas de nutrición, y actitudes vergonzosas, con arrugas, observaciones, sueños, vigilia, profecías, declaraciones de amor y de odio, bestias, sacudidas, idilios, creencias políticas, negaciones, dudas, afirmaciones, impuestos ${ }^{20}$.

En esta declaración no abandonaba todavía Neruda el material lírico de las dos primeras Residencias, pero sí dejaba entrever, a decir de Rodríguez Monegal, «la clave de su nueva estética»: ensanchar «el campo de la poesía para incluir todo en ella» ${ }^{21}$. «Traigo la palabra y el sueño, la realidad y el juego inconsciente, / lo cual quiere decir que yo trabajo con toda la realidad»22, había escrito también González Tuñón, en un poema publicado en Todos bailan (1935). 
Es interesante observar la presencia del poeta argentino en la revista dirigida por Neruda. En el prólogo a la segunda edición de La rosa blindada (1962), recuerda González Tunón haber participado en la revista con el poema «Los nueve negros de Scottsboro», una composición con claro propósito de denuncia ${ }^{23}$. Sin embargo, no fue este el poema que apareció en la revista, sino el titulado «Poema caminando», que tal vez fuera el que mejor se ajustaba al esquema enunciado por Neruda. Hay en el poema de González Tuñón: «fuentes agotadas», «grifos secos», "estaciones desiertas con musgo y con relojes», «olor reciente de niños acostados», «estatuas con frío», «bitácoras solas», «ciegos con telescopios», «trasnochados maniquíes», «mingitorios», «pájaros sin alas»...; un inventario poético, en suma, que brota de la misma veta nerudiana, de ese «mundo destruido» 24 que fascinara a Amado Alonso y enfureciera al purista Juan Ramón.

No obstante, el poeta militante que hay en González Tuñón es capaz de extraer, a través de la contienda social, la masa vivífica que aguarda tras la escara de ese mundo en descomposición:

Se han visto marchas de hambre sobre flamantes villas $\mathrm{y}$ de burgueses muertos vientres agujereados y de filas de mineros fusilados<smiles>[AlH2]</smiles>

Hay la revuelta próxima que estallará de pronto como la luz tan súbita que inventa la ventana.

Hay posibilidades para la poesía.

Hay mañana ${ }^{25}$.

A diferencia de Neruda, la obra de González Tuñón evidenciaba ya ese paso de lo individual a lo colectivo ${ }^{26}$, de la poesía íntima a la poesía civil, una empresa que estaba a punto de emprender la poesía del chileno.

\section{BAJO LAS NUEVAS BANDERAS}

En enero de 1936, González Tuñón había regresado a Buenos Aires e inmediatamente entraba a colaborar activamente en la revista Unidad por la defensa de la cultura, órgano de la Agrupación de Intelectuales, Artistas, Periodistas y Escritores (AIAPE) de la Argentina, en cuyo editorial se llamaba «a apretar filas» contra el fascismo.

Mientras tanto, se publicaba en España el último número de Caballo verde, en el que

Neruda rendía homenaje a la figura de Gustavo Adolfo Béquer, y se reeditaba en $\mathrm{Ma}$ drid los Veinte poemas, bajo el título de Primeros poemas de amor. Eran momentos, no obstante, de grave intensidad política: en febrero debían celebrarse las elecciones generales, a las que concurrirían las izquierdas en torno a un bloque unitario llamado «Frente Popular», que finalmente se alzaría con la victoria el 16 de febrero. El ambiente intelectual madrileño vivía, de forma paralela, un momento de extraordinaria actividad militante: no hubo en los meses previos al inicio de la guerra civil, tertulia en la que no se discutiera de política; banquete o reunión que no acabara con la lectura de una proclama; ni hoja literaria en la que no apareciera uno de esos manifiestos a los que a un nombre le suceden trescientas firmas. Es indudable que la conciencia poética de Neruda se fue empapando de esa nueva realidad, de la energía y la vehemencia artística que desprendía aquella atmósfera excepcional. María Zambrano, en su conocido ensayo Los intelectuales en el drama de España, publicado en Chile en 1937, había advertido ya genéricamente la substancia transformadora que entrañaba la vida española de ese tiempo:

Es la revolución, que se desarrolla en un tiempo de mayores dimensiones que el normal. En esas horas anchas, hondas, placenta de la época que está al surgir, en esos espacios en que el tiempo se recoge como un seno inmenso del que entre sangre y angustia nacen los nuevos pensamientos. Pensamientos nunca pensados, pero presentidos, y de tan evidente necesidad que al ser enunciados quedan exactamente ajustados al hueco de esperanzas y necesidades que los aguardan ${ }^{27}$.

23

Sobre este poema informa Beatriz Sarlo que González Tuñón se refiere a unos muchachos negros «a quienes, en marzo de 1931, un grupo de jóvenes blancos, en Jackson
County, Alabama, acusó de ataques y violaciones. El partido comunista de Estados Unidos tomó la cuestión, denunciando un caso de flagrante injusticia originada en el racismo. Estos negros fueron sen- tenciados a muerte, pero ante una movilización gigantesca, la sentencia fue conmutada. La cuestión tuvo proyección mundial en la prensa comunista» (Una modernidad periférica: Buenos Aires 1920 y 1930, Buenos Aires, Nueva Visión, 1988, p. 172).

24

Amado Alonso, op. cit., p. 84.

25

Raúl González Tuñón, «Poema caminando", Caballo verde para la poesía, núm. 1.

26

En un texto titulado "Los escritores y la realidad» (El otro lado de la estrella, Montevideo-Buenos Aires, Sociedad Amigos del Libro Rioplatense, 1934, p. 23), demuestra Tuñón haber asimilado las teorías marxistas en torno a la función del arte: "El arte no puede ser, no debe ser neutral. [...] El Arte debe responder a convicciones sociales en una sociedad dividida en clases».

27

María Zambrano, Los intelectuales en el drama de España y escritos de la guerra civil, Madrid, Trotta, 1998, p. 112.

¿Raúl, te acuerdas...? Neruda y González Tuñón ante la Guerra Civil española PEDRO MENDIOLA OÑATE 


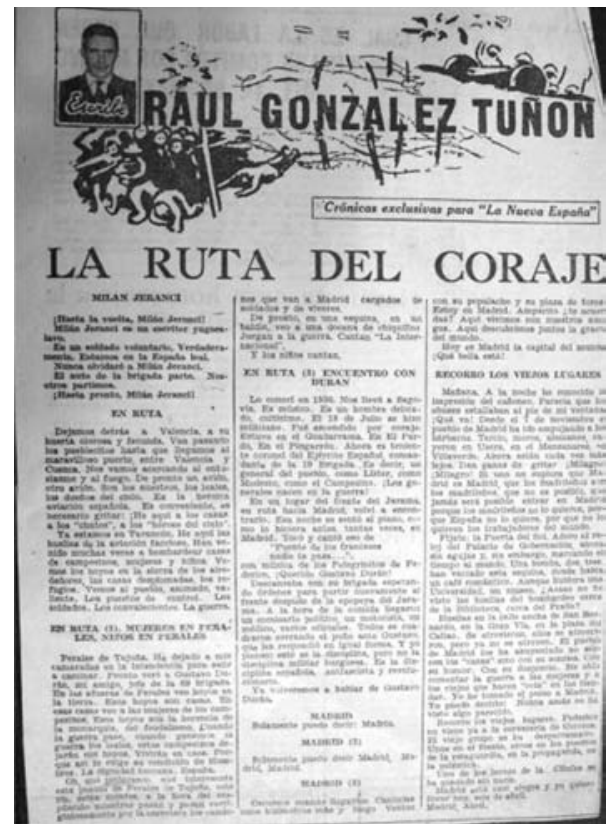

Crónicas de González Tuñón sobre la Guerra Civil Española.

Así parece reconocerlo Neruda en una carta abierta, dirigida a Serrano Plaja y Salas Viu en 1940:

Vosotros, cuántos! todos, habéis aclarado tanto mi pensamiento, me habéis dado tan singular $y$ tan transparente amistad.

[...]

Me habéis mostrado una amistad alegre y cuidada, y vuestro decoro intelectual me sorprendió al principio: yo llegaba de la envidia cruda de mi país, del tormento. Desde que me acogisteis como vuestro, disteis tal seguridad a mi razón de ser, y a mi poesía, que pude pasar tranquilo a luchar en las filas del pueblo. Vuestra amistad y vuestra nobleza me ayudaron más que los tratados. Y hasta ahora, este senci-

28

Pablo Neruda, «Envío: a Arturo Serrano Plaja y Vicente Salas Viu», en Para nacer he nacido, Barcelona, Seix Barral, 2002, p. 73.

\section{9}

César Vallejo, «Los enunciados populares de la guerra española», en Enunciados de la guerra española, Buenos Aires, Rodolfo Alonso Editor, 1975, p. 29.

\section{0}

Pablo Neruda, «Reunión bajo las nuevas banderas», Obras completas I, op. cit., pp. 364-365.

31

Raúl González Tuñón, «Prólogo» a La rosa blindada, Buenos Aires, Ediciones Horizonte, 1962, p. 9.

32

Citado por Elvio Romero, Miguel Hernández, destino y poesía, Buenos Aires, Losada, 1979, p. 77.

\section{3}

Pablo Neruda, "Explico algunas cosas», España en el corazón, Madrid, Ejército del Este, 1938, p. 21.

¿Raúl, te acuerdas...? Neruda y González Tuñón ante la Guerra Civil española PEDRO MENDIOLA OÑATE llo camino que descubro, es el único para todos los intelectuales ${ }^{28}$.

«iCuántos nuevos enunciados de grandeza humana y de videncia cívica van brotando! ${ }^{29}$, dirá también César Vallejo. El poema que precede a España en el corazón en Tercera residencia, "Reunión bajo las nuevas banderas», da cuenta de esos nuevos enunciados, de ese nuevo camino elegido, no tanto por la vía ideológica como por la vía histórica:

Yo de los hombres tengo la misma mano herida, yo sostengo la misma copa roja

e igual asombro enfurecido:

un día

palpitante de sueños

humanos, un salvaje

cereal ha llegado

a mi devoradora noche

para que junte mis pasos de lobo

a los pasos del hombre ${ }^{30}$.

\section{POR UNA POESÍA SIMULTÁNEA A LOS HECHOS}

En agosto de 1936 hacía su aparición el primer número de El Mono Azul, hoja informativa de la Alianza de Intelectuales Antifas-
34

Pablo Neruda, «Madrid», Ibi- Pablo Neruda, "Generales dem, p. 18.

\section{5}

traidores», Ibidem, p. 24. cistas que amalgamaba las crónicas del frente, con poemas de la guerra y tácticas de combate para el soldado. En su quinto número, 24 de septiembre de 1936, aparecía un poema anónimo titulado "Canto a las madres de los milicianos muertos». Hacía tres meses que había estallado la guerra civil española y empezaba a confirmarse el asesinato en Granada de $\mathrm{Fe}$ derico García Lorca. En Buenos Aires acababa de publicarse La rosa blindada con una tirada excepcional y 8 documentos de boy de Raúl González Tuñón. Años después, el poeta argentino quiso ver en el cambio que inaugura la mencionada composición de Neruda la huella de su poesía combativa:

si Asturias estaba lejos y él necesitaba ser testigo directo, el Cuartel de la Montaña quedaba a poca distancia de su 'Casa de las flores' y una mañana de julio del 36 vio a los milicianos marchar al asalto de aquella fortaleza y abatirla. Fue cuando escribió el primer poema distinto, Canto a las madres de los milicianos muertos. Y como nosotros habíamos blindado la rosa, él 'blindó el viento' ( «...como una cortina de viento blindado» $)^{31}$.

En otro lugar, recuerda también González Tuñón las discusiones en casa de Neruda sobre «la doble función de la poesía en épocas de ruptura, de transición, en épocas revolucionarias»32. Y a aquellas reuniones debe de aludir seguramente Neruda en otro poema publicado en El Mono Azul (núm. 22, 1 julio 1937), bajo el título de «Es así»:

\section{Raúl te acuerdas? \\ Te acuerdas, Rafael? \\ Federico, te acuerdas, \\ debajo de la tierra... ${ }^{33}$.}

El poema es una primera redacción del famoso «Explico algunas cosas», en el que $\mathrm{Ne}$ ruda registra la transformación que está sufriendo su poesía, su «rostro cambiado para siempre por la luz de la sangre» ${ }^{34}$ :

\section{Preguntaréis por qué su poesía no nos habla del sueño, de las hojas. de los grandes volcanes de su país natal? venid a ver la sangre por las calles.... ${ }^{35}$.}

La toma de partido por parte de Neruda en favor de la República, le valió su destitución como cónsul en Madrid. Finalmente, se 
vio obligado a abandonar la capital y, después de un periplo por distintas ciudades, se establecería en París, donde funda con Vallejo el Grupo Hispanoamericano de Ayuda a España. Trabajará también activamente en la organización del II Congreso de Intelectuales en Defensa de la Cultura que ha de celebrarse en 1937, y editará con Nancy Cunard la revista Los poetas del mundo defienden al pueblo español, en la que entre otros poetas aparece también la firma de González Tuñón. A principios de 1937, Tuñón se embarcaba como corresponsal de El Diario, junto a Cayetano Córdova Iturburu, enviado del diario Crítica, para participar en el Congreso de Intelectuales. El 10 de marzo de 1937 el cónsul español en Marsella le extiende un salvoconducto para que las milicias del Frente Popular faciliten su entrada y su circulación por el territorio nacional hasta Valencia. El 29 de marzo González Tuñón ya se encuentra en la capital valenciana, así lo atestigua otro documento acreditativo inscrito en el Registro de Periodistas Extranjeros y expedido por la Oficina de prensa del Ministerio de Estado.

No vamos a entrar a valorar ahora las circunstancias del Congreso, hay bibliografía suficiente para tener una idea más o menos clara de sus circunstancias y su alcance ${ }^{36}$, sino tratar de analizar la presencia de Neruda y de González Tuñón en tal ocasión. El Congreso tuvo lugar en Valencia, Madrid y Barcelona, entre los días 4 y 11 de julio de 1937. Acudieron entre otros: Mikhail Koltzov, Ilya Eherenburg y Alexis Tolstoi (URSS); Julien Benda, Louis Aragon, André Malraux y Tristan Tzara (Francia); Bertolt Brecht, Heinrich Mann y Ludwig Renn (Alemania); Stephen Spender y Wystan Auden (Inglaterra) y Langston Hughes (Estados Unidos); Alejo Carpentier, Nicolás Guillén y Juan Marinello (Cuba); Vicente Huidobro (Chile), César Vallejo (Perú) y Octavio Paz y Carlos Pellicer (México); además de los españoles y los ya mencionados. A pesar de las expectativas que este repertorio pudieran suscitar, en opinión de algunos -como el entonces presidente de la República, Manuel Azaña-, la significación del congreso fue nula y la participación intelectual insuficiente y de escaso renombre ${ }^{37}$.

González Tuñón, junto con Pablo Rojas Paz y Cayetano Córdova Iturburu, formaban la delegación argentina. Raúl era miembro del Partido Comunista Argentino, miembro del
Comité Directivo de la Alianza de Intelectuales Antifascistas y de la AIAPE (Agrupación de Intelectuales, Artistas, Periodistas y Escritores), y acudía además al Congreso en calidad de ponente. Su primera intervención, escueta como la mayoría, tuvo lugar en la Sala Consistorial del Ayuntamiento de Valencia en la jornada de apertura, el 4 de julio, y hay en ella una declaración de hermandad americana que bien pudiera haber firmado el propio Neruda:

Vengo de los grandes ríos y de las altas montañas, de las claras y las oscuras, altas y chatas ciudades de un continente que habla en español, de un continente de veinte y tantos países iguales y distintos, donde, desde la selva de la canción autóctona hasta el puerto de los cantos internacionales; desde el caos caliente de los trópicos y los grandes silencios blancos del Sur; desde el laberinto de las explotaciones minerales y los dorados campos trigueros [...]: ochenta millones de americanos, criollos o gringos viven pendientes de los sucesos de España, siguiendo con alternativas de angustia y alegría la lucha de los españoles contra la invasión fascista internacional38.

Y en la clausura del Congreso, que fue celebrada en París donde se preparaba por esas mismas fechas la Exposición Internacional de París ${ }^{39}$ en la que sería presentado El Guernica de Picasso, González Tuñón emplazaba a la acción internacional, al combate intelectual en similares términos a los utilizados años atrás en su perseguida revista Contra:

...el escritor debe servirse del arma que sabe manejar mejor, la pluma. La pluma de un escritor digno de tal nombre no debe ser servil. Pero hoy un escritor auténtico moja su pluma antes en la sangre que en la tinta; y si esta pluma no se convierte, más que nunca, en un arma, vale más que se pudra en la inacción. [...] España es hoy nuestra pasión. Si no combatimos en su suelo, seamos en el exterior sus soldados de una forma u otra. Brigadas de choque del pensamiento internacional [...]. No nos avergoncemos de haber puesto, por una vez, nuestra pluma al servicio de algo -pues ese algo es España nada menos. Ese algo es el mundo, es el destino del hombre ${ }^{40}$.

No tenemos, en cambio, intervenciones de Neruda en el congreso, aunque es evidente el peso intelectual que tenía el chileno a esas alturas. Tras la destitución de su cargo en el Consulado y su salida de España, funda en $\mathrm{Pa}$ rís, como ya hemos dicho, el Grupo Hispa-
36

Véase Manuel Aznar Soler y Luis Mario Schneider, II Congreso Internacional de Escritores Antifascistas (1937), Barcelona, Editorial Laia, 1978-1979, 3 vols.; Federico Suárez, Intelectuales antifascistas, Madrid, Rialp, 2002.

37

«El Congreso no ha valido nada. Ha venido poca gente y poquísima de renombre. La aportación española no ha sido más lucida. A la inauguración asistió parte del Gobierno, con su Presidente. Después los han llevado a Madrid, a celebrar dos sesiones en un cine, $y$ varios banquetes. Aguantaron una noche de bombardeo»: Manuel Azaña, Memorias políticas y de guerra, II, Barcelona, Editorial Crítica, 1981, p. 141 (10 julio 1937).

38

Véase Manuel Aznar Soler y Luis Mario Schneider, II Congreso Internacional de Escritores Antifascistas (1937). Volumen III. Ponencias, documentos y testimonios, ed. cit., pp. 40-41. El texto fue publicado en Nueva Cultura, Valencia, núms. 4-5, junio-julio 1937.

39

Cfr. Josefina Alix Trueba (dir.), Pabellón español. Exposición In ternacional de París 1937, Madrid, Ministerio de Cultura, 1987.

40

Manuel Aznar Soler y Luis Mario Schneider, op. cit., págs. 236237. El texto fue publicado en Commune, París, núm. 49, septiembre 1937, pp. 60-62.

¿Raúl, te acuerdas...? Neruda y González Tuñón ante la Guerra Civil española PEDRO MENDIOLA OÑATE 
41

Cfr. Luis Mario Schneider, II Congreso Internacional de Escritores Antifascistas (1937). Volumen I. Inteligencia y Guerra Civil española, ed. cit., pp. 80-81.

42

Raúl González Tuñón, «Estuve en Madrid en 1935. Estuve en $\mathrm{Ma}$ drid en 1937», en Tierra, Santiago, núm. 4, octubre-noviembre 1937, pp. 2-4.

43

Raúl González Tuñón, «España en el corazón», Tierra, Santiago, núm. 5, diciembre 1937, p. 37.

\section{4}

Paul Claudel, A los mártires españoles, versión española de Jorge Guillén, Sevilla, Secretaría de Ediciones de la Falange, 1937 , p. 11.

45

Volodia Teitelboim, Huidobro, la marcha infinita, Santiago, BAT, 1995, p. 231.

46

Cito por Pablo Neruda, «Federico García Lorca», Hora de España, Barcelona, núm. 3, marzo 1937, p. 77

47

Arturo Serrano Plaja, "A diestra y siniestra. (Los intelectuales y la guerra)», en Hora de España, Valencia, núm. 7, julio de 1937 p. 30.

48

Raúl González Tuñón, art. cit.

¿Raúl, te acuerdas...? Neruda y González Tuñón ante la Guerra Civil española PEDRO MENDIOLA OÑATE nomericano de ayuda a España y consigue un empleo en la AEAR (Association des Écrivains et Artistes Revolutionaires) que dirigía Louis Aragon. Sea como fuere, y a pesar de la proverbial desmaña burocrática del chileno, Neruda comenzó a organizar la sección hispanoamericana del Congreso, con la ayuda de Delia del Carril y de Amparo Mom, esposa de Raúl González Tuñón. Ya en Valencia sería propuesto para ocupar la presidencia, junto con otros asambleístas, en representación de América del Sur ${ }^{41}$.

Al término del Congreso, Neruda regresaba de nuevo a Chile acompañado por tres argentinos: Delia del Carril, Amparo Mom y Raúl González Tuñón.

\section{LOS LIBROS DE LA GUERRA}

Establecidos en Santiago, ambos poetas siguen trabajando juntos, dan conferencias, participan en la creación de la Alianza de Intelectuales de Chile en Defensa de la Cultura, pero sobre todo escriben. El 8 de noviembre de 1937 Neruda y González Tuñón dan el discurso inaugural en la primera reunión de la Alianza de Intelectuales de Chile que preside el poeta chileno: el texto de Raúl, una emotiva defensa de la acción republicana en la defensa de Madrid, prefigura el tono de su siguiente libro de poemas La muerte en Madrid $^{42}$. González Tuñón prepara además un libro de crónicas de guerra Las puertas del fuego, que será editado en Chile en 1938. Neruda, por su parte, ultima la edición de España en el corazón. Himno a las glorias del pueblo en la guerra, que aparece en Santiago en noviembre de 1937, del que se editan 2000 ejemplares.

Es probable que la primera valoración sobre el poemario de Neruda sea precisamente la del poeta argentino, publicada en la revista Tierra, en su número de diciembre de 1937.

González Tuñón comienza su reseña con una curiosa declaración:

El poeta es siempre poeta. ¿Se permite a Claudel que haga poesía católica, es decir, propaganda también, porque Claudel es un gran poeta? Pues entonces -aunque no nos interesen los mezquinos, los cobardes, los reaccionarios- digamos a quienes han comentado por ahí con sorpresa -con miedo, con resentimiento- el libro de Pablo Neruda puede hacer poesía revolucionaria porque es un gran poeta, nada menos que uno de los más grandes poetas de nuestro tiempo $0^{43}$.

Claudel había compuesto en marzo del 37 su poema «A los mártires españoles», que había aparecido originariamente como prefacio al libro La persécution religieuse en Espagne (París, Plon, 1937) de Joan Estelrich, y que fue utilizado de forma inmediata por el servicio de propaganda fascista ${ }^{44}$. Por otro lado, puede referirse también Tuñón cuando alude a esos comentarios adversos, a cierto libelo aparecido en la prensa de Santiago, en el que, según Volodia Teitelboim, Huidobro, por puro resentimiento literario, «asumió la identidad apócrifa de un franquista sarcástico» ${ }^{45}$ para ridiculizar la obra de Neruda y los ideales a los que estaba consagrada. Lo interesante en todo caso sea tal vez la motivación de este párrafo justificatorio.

Es claro que en ese momento, la obra de Neruda no es fruto de la militancia sino de la solidaridad. En París, en un homenaje a García Lorca en febrero de 1937, todavía declaraba Neruda: «no soy político ni he tomado nunca parte en la contienda política, y mis palabras, que muchos habrían deseado neutrales, han estado teñidas de pasión», y pide comprensión ante quienes quizá esperaban de él «tranquilas palabras poéticas distanciadas de la tierra y de la guerra» ${ }^{46}$. Tal vez, González Tuñón sintió igualmente la necesidad de proteger la nueva dirección poética de Neruda, ante quienes alertaban de los «apresurados izquierdistas», de los «neutrales de ayer» que ahora se daban codazos «para ingresar en las organizaciones, para hacer frases más revolucionarias que nadie, para sentirse más pueblo que el pueblo mismo»47. Quizás por eso, González Tuñón coloca el libro de Neruda al margen de las circunstancias que lo originan, al margen de la mera condición ancilar: «Cuando todo pase, cuando los bombardeos, los generales, el triunfo del pueblo, sean historia... España en el corazón quedará, totalmente, como documento y como obra poéti$\mathrm{ca}$, pero por lo menos como obra poética» ${ }^{48}$. Tuñón además, subrayaba el nuevo acento de la poesía nerudiana advirtiendo: «Pablo sigue siendo Pablo Neruda. No podemos preferir al Pablo Neruda de antes o al Pablo Neruda de ahora porque es el todo Pablo Neruda el que hace el poeta. En Temuco y en Rangoon, en Buenos Aires y en Cuenca, allí donde estuvo 
el poeta estuvo la poesía, allí donde está $\mathrm{Ne}$ ruda la poesía está, delicada o tremenda, realista o lírica, siempre revolucionaria porque siempre poesía» ${ }^{49}$.

Los caminos de Neruda y González Tuñón se separan cuando el chileno es nombrado Secretario en la Embajada de Chile en México. El argentino todavía permanecería en Chile por algún tiempo, donde publica Himno de pólvora (1943). Libro este profundamente nervado por la experiencia comunista, al igual que la poesía inmediatamente posterior de Neruda, donde se encuentra «cada vez más cerca del himno, de la letanía, de la litúrgica enumeración» ${ }^{50}$, como había determinado María Zambrano en la poesía del chileno.

Es claro que ambos poetas sufrieron un proceso evolutivo similar hacia la poesía cívica y de esta hacia la poesía militante, y no cabe duda de que en ese proceso la guerra civil española fue un detonante esencial. Atrás quedarían «la música de los puertos», la sordidez arrabalera; atrás quedarían también las lilas, la «metafísica cubierta de amapolas»: era el tiempo del «poema en armas», del «lenguaje del frente»; aquel lenguaje «fuerte, conciso, breve» ${ }^{51}$, que pidiera un Comisario político del 5. ${ }^{\circ}$ Regimiento; o aquella «urgente gramática necesaria» de Rafael Alberti, que a través de «la palabra precisa», el «verbo exacto» y el «justo adjetivo» devolviera a la lengua "el inédito asombro de crear» ${ }^{52}$. Es posible que en ese nuevo derrotero Neruda viera en los versos de su amigo argentino una senda favorable. Pero la poesía que generó la guerra civil abrió un camino demasiado vasto para distinguir claramente las huellas de una sola traza, y no es difícil que se crucen o se difuminen los rastros entre Neruda y González Tuñón, entre César Vallejo y Nicolás Guillén; entre estos y los poetas españoles: Alberti, Miguel Hernández, Emilio Prados o Aleixandre; incluso, salvando las distancias del idioma, entre todos ellos y Wystan Auden o Bertolt Brecht.

Evidentemente, la fortuna literaria de $\mathrm{Ne}$ ruda y de González Tuñón es muy desigual, pero la obra de ambos mantiene esa intuición perenne que convoca a otras voces y trasciende generaciones y movimientos literarios. A partir de los años cuarenta, ambos siguieron inmersos en un tiempo heroico, y su poesía estuvo inspirada en cada momento por un viento nuevo, que no pide paso, que se adelanta, como dice Tuñón en un poema; un viento que sólo respeta a los caídos y a los que luchan, a que los agonizan y a los que esperan; un viento que sólo respeta a las estatuas -vale decir poetas- que merecen permanecer de pie sobre las ruinas.
49

Ibidem.

50

María Zambrano, "Pablo Neruda o el amor a la materia», en Hora de España, Barcelona, noviembre 1938, p. 42.

51

Carlos (Comisario político del 5.은 Regimiento), «El lenguaje del frente», Milicia popular, Madrid, año I, núm. 60, 3 de octubre de 1936.

52

Rafael Alberti, «De ayer para hoy", Entre el clavel y la espada, en Poesía II, Barcelona, Seix Barral, 2003, p. 281. 